\title{
CONSCIÊNCIA FONOLÓGICA E DESEMPENHO ESCOLAR
}

\author{
Phonological awareness and school performance
}

\author{
Patrícia Aparecida Zuanetti ${ }^{(1)}$, Andréa Pires Corrêa Schneck ${ }^{(2)}$, Alessandra Kerli da Silva Manfredi ${ }^{(3)}$
}

\begin{abstract}
RESUMO
Objetivos: verificar a relação entre consciência fonológica e o desempenho acadêmico de escolares, e averiguar se a ordem de preferência para as tarefas acadêmicas é a mesma ordem conseguida por esta criança em seu desempenho. Métodos: avaliou-se 24 crianças de uma sala da $2^{\mathrm{a}}$ série do ensino fundamental de uma escola pública, aplicando a prova de consciência fonológica por produção oral e o teste de desempenho escolar. Excluíram-se todos os alunos que apresentavam distúrbios fonológicos. Resultados: existe associação entre ordem de preferência e resultado apenas nas tarefas de aritmética e escrita, já na leitura não existe. Em relação ao desempenho nas tarefas de consciência fonológica, o grupo com desempenho escolar médio foi mais hábil em tarefas que envolviam síntese fonêmica, rima, segmentação fonêmica e manipulação fonêmica quando comparados aos alunos com desempenho acadêmico inferior. Quanto à correlação, esta foi positiva e forte entre as variáveis estudadas (consciência fonológica, desempenho escolar, leitura, escrita e aritmética). Conclusões: quanto mais desenvolvida é a consciência fonológica, melhor é a performance do aluno; Tarefas de rima, síntese, segmentação e manipulação fonêmica estão mais relacionadas à alfabetização. Existe associação entre ordem de preferência e resultado nas tarefas de aritmética e escrita.
\end{abstract}

DESCRITORES: Baixo Rendimento Escolar; Linguagem Infantil; Estudos de Linguagem

\section{INTRODUÇÃO}

Nos países ocidentais, a instituição escolar tem grande importância, pois é o lugar de excelência em que se realiza a educação, possuindo grande influência na maturação de cada pessoa ${ }^{1}$. O bom desempenho escolar pode favorecer a superação de dificuldades, no entanto, os empecilhos encontrados para se ter um desempenho satisfatório, podem acentuar problemas educacionais e emocionais ${ }^{2}$.

Para a criança aprender a ler e escrever, ela deve entender $\mathrm{o}$ elo entre fonemas e grafemas. Essa ligação entre sons e letras é estabelecida através do princípio alfabético da escrita onde, palavras

(1) Fonoaudióloga; Aprimoranda no Hospital das Clínicas da Faculdade de Medicina de Ribeirão Preto.

(2) Fonoaudióloga; Contratada do setor de Fonoaudiologia do Hospital das clínicas da Faculdade de Medicina de Ribeirão Preto da Universidade de São Paulo; Mestre pelo Departamento de Oftalmologia, Otorrinolaringologia e Cirurgia de Cabeça e Pescoço da Faculdade de Medicina de Ribeirão Preto da Universidade de São Paulo.

(3) Fonoaudióloga; Contratada do setor de Fonoaudiologia do Hospital das Clínicas da Faculdade de Medicina de Ribeirão Preto da Universidade de São Paulo; Mestre em Saúde Pública pela Escola de Enfermagem da Universidade de Ribeirão Preto. escritas contêm combinações de unidades visuais letras ou combinações de letras - que são sistematicamente relacionadas às unidades sonoras das palavras - fonemas ${ }^{3}$.

O princípio alfabético é uma condição necessária para a aquisição da leitura e escrita, e três fatores são necessários para a aprendizagem deste princípio: consciência de que é possível segmentar a língua falada em unidades distintas, consciência de que tais unidades reaparecem em diferentes palavras e o conhecimento das regras de correspondências grafo-fonêmicas ${ }^{4}$. Os dois primeiros constituem a consciência fonológica.

Logo, a consciência fonológica permite a identificação de rimas, de aliteração e de fonemas que podem ser manipulados para a criação de novas palavras. Também faz da linguagem um objeto de pensamento, possibilitando a reflexão sobre os sons da fala, o julgamento e a manipulação da estrutura sonora das palavras ${ }^{3}$. É uma habilidade definida como a capacidade para refletir sobre a estrutura sonora da fala bem como manipular seus componentes estruturais apresentando uma estreita relação com o aprendizado do código escrito ${ }^{5}$.

Se a criança não tiver estas habilidades (ler/ escrever/calcular) desenvolvidas, o risco de frustrações tanto no momento da alfabetização quanto 
posteriormente com certeza acontecerão e trarão possíveis complicações para a vida deste, tanto em relação a uma vida em sociedade, como a visão que um indivíduo tem de si próprio (auto-estima) ${ }^{2}$.

No momento da avaliação fonoaudiológica é importante que o aluno não se sinta incapaz logo nas primeiras tarefas, diminuindo assim sua motivação, é preciso que se inicie a avaliação por tarefas em que o aluno obtenha melhores resultados, para que ele perceba que há coisas que ele consegue realizar satisfatoriamente.

Os objetivos deste estudo são verificar a relação entre consciência fonológica e o desempenho acadêmico de escolares, analisar quais tarefas de consciência fonológica, os alunos com desempenho satisfatório (médio) são melhores que os alunos com desempenho inferior, e averiguar se a ordem de preferência para as tarefas acadêmicas dita por um aluno é a mesma ordem que a do desempenho nestas tarefas conseguida por este.

\section{MÉTODOS}

Antes da aplicação das provas, os responsáveis pelos estudantes foram informados quanto ao projeto e assinaram o termo de consentimento livre e esclarecido.

Participaram das avaliações 23 crianças, sendo 12 do sexo feminino $(52,2 \%)$ e 11 do masculino $(47,8 \%)$, com idade média de 8,5 anos.

Todos os alunos estavam freqüentando a $2^{2}$ série do ensino fundamental de uma escola pública do município de Ribeirão Preto e, pertenciam à mesma sala de aula.

Os critérios de inclusão no grupo de estudo foram: crianças que não possuíam distúrbio fonológico, podendo a dificuldade do sujeito estar na percepção, na produção ou na organização das regras do sistema fonológico.

Todos os sujeitos passaram pela mesma seqüência de avaliações e esta foi realizada de maneira individual. Os testes realizados foram:

- avaliação dafonologia(ABFW-área fonológica $)^{6}$. utilizado para o critério de inclusão.

- teste de desempenho escolar (TDE) ${ }^{7}$ : utilizado com o objetivo de quantificar o desempenho do acadêmico em leitura, escrita e aritmética. Através deste pode-se obter os escores brutos nos três subtestes: de escrita (escrita do próprio nome e de palavras isoladas apresentadas sob a forma de ditado), o de aritmética (solução de problemas oralmente e de operações aritméticas por escrito) e o de leitura (reconhecimento de palavras isoladas do contexto). No teste não há a presença de pseudopalavras. Ele é utilizado para avaliação de indivíduos que estejam entre a $1^{\text {a }}$ e $6^{\underline{a}}$ série do ensino regular fundamental.

- aplicação da prova de consciência fonológica por produção oral (PCFO) ${ }^{8}$ : avalia a habilidade das crianças de manipular os sons da fala. A PCFO é composta por dez subtestes sendo estes: síntese silábica e fonêmica, aliteração, rima, segmentação silábica e fonêmica, transposição silábica e fonêmica e manipulação silábica e fonêmica.

Antes da realização das provas do TDE, foi perguntado ao aluno qual dentre as tarefas (ler, escrever e realizar contas de matemática) ele mais gostava, qual ele selecionava em segundo lugar e qual era a que ele menos preferia. Esta preferência foi comparada ao desempenho que ele obteve nas provas.

Tanto o TDE, quanto o PCFO oferecem os resultados através de escores e nestes dados aplicouse testes estatísticos, que serão citados no decorrer dos resultados.

Com a obtenção do escore total (soma dos escores brutos nos três subtestes - leitura, aritmética e escrita) no TDE e a partir da tabela de padronização fornecida pelo próprio teste para a $2^{a}$ série, os alunos deste estudo foram classificados em três níveis de desempenho acadêmico: inferior (escore total abaixo de 86), médio (escore total entre 87 e 105) e superior (escore total acima de 105).

Os testes foram aplicados na biblioteca da própria escola pela responsável pelo estudo e, de maneira individual. Todos os testes foram aplicados no mesmo momento e duraram, em média, 40 minutos.

O projeto de pesquisa foi avaliado e aprovado pelo Comitê de Ética do Hospital das Clínicas de Ribeirão Preto (HCRP - USP), sob o processo de número 10156/2006.

Os testes estatísticos utilizados foram qui-quadrado, Wilcoxon (ambos com 0,05 nível de significância) e correlação de Pearson.

\section{RESULTADOS}

\section{Desempenho escolar}

Encontrou-se que dos 23 indivíduos, apenas um teve desempenho acadêmico superior $(4 \%)$ e os demais se dividem igualmente entre médio (11 indivíduos, 48\%) e inferior (11 indivíduos, 48\%).

$\mathrm{Na}$ Figura 1, observa-se que aritmética foi a tarefa predileta entre os sujeitos desta pesquisa (11 indivíduos, 47,8\%), mas o melhor desempenho da sala foi em leitura (11 crianças, 47,8\%). Doze alunos $(52,2 \%)$ citaram a leitura como segunda preferência. A escrita, por sua vez, foi com mais freqüência a tarefa menos preferida (11 alunos, $47,8 \%$ ) e a que os alunos apresentaram pior desempenho (16 indivíduos, 69,6\%). 


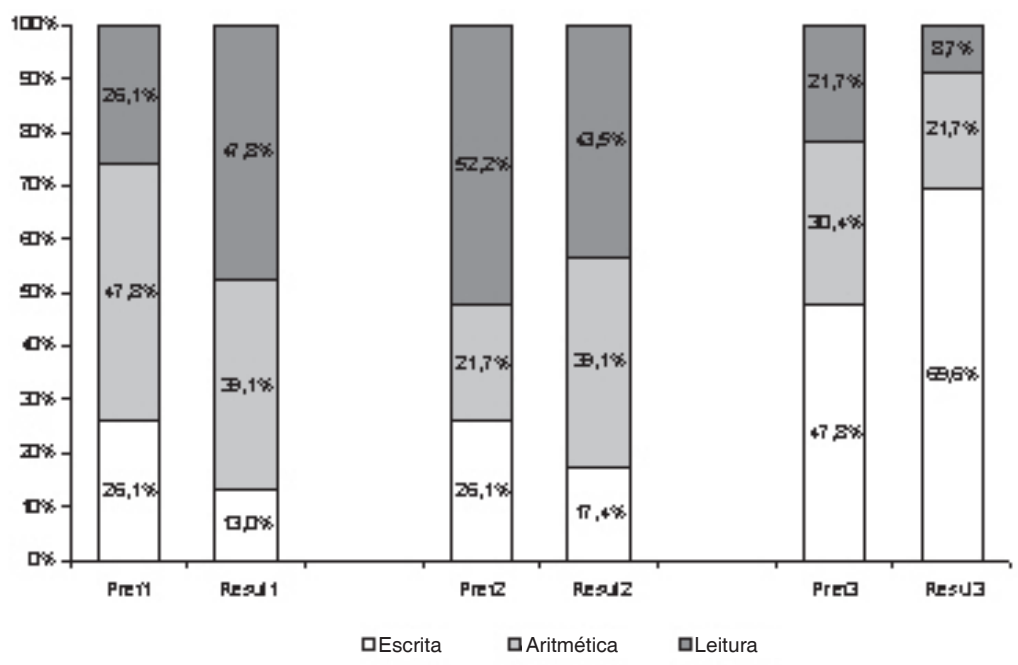

Figura 1 - Ordem de preferência e resultado nas tarefas acadêmicas

Através do teste qui-quadrado para associação, com nível de significância de 0,05, calculou-se se havia associação entre ordem de preferência e ordem de resultado em cada uma das tarefas escolares estudada.

Na escrita, o p-valor foi de 0,0199, o que demonstra que há associação entre preferência e desempenho. Na aritmética, o p-valor foi de 0,026, o que comprova a existência de associação entre ordem de preferência e desempenho. Já na leitura, o pvalor foi de 0,116 , confirmando que nesta tarefa não houve associação, pois poucas crianças a citaram como sendo sua ocupação preferida, mas quase metade da sala teve melhor desempenho nesta.

Também em relação à preferência e desempenho, constatou-se que 21 (91\%) crianças tiveram pelo menos uma tarefa classificada com ordem de preferência e ordem de resultados iguais e, que 11 alunos (48\%) dos acadêmicos deste estudo tiveram a mesma ordem para preferência e para desempenho nas três tarefas.

\section{Consciência fonológica}

$\mathrm{Na}$ Figura 2, que apresenta os escores médios dos alunos em cada tarefa do teste por nível de desempenho escolar, observa-se que a pontuação média dos alunos com desempenho médio foi superior ou, em apenas um caso (síntese silábica), igual ao escore médio dos alunos com inferior desempenho. Como o grupo com desempenho superior é formado apenas por um aluno, não é possível compará-lo com os demais. No

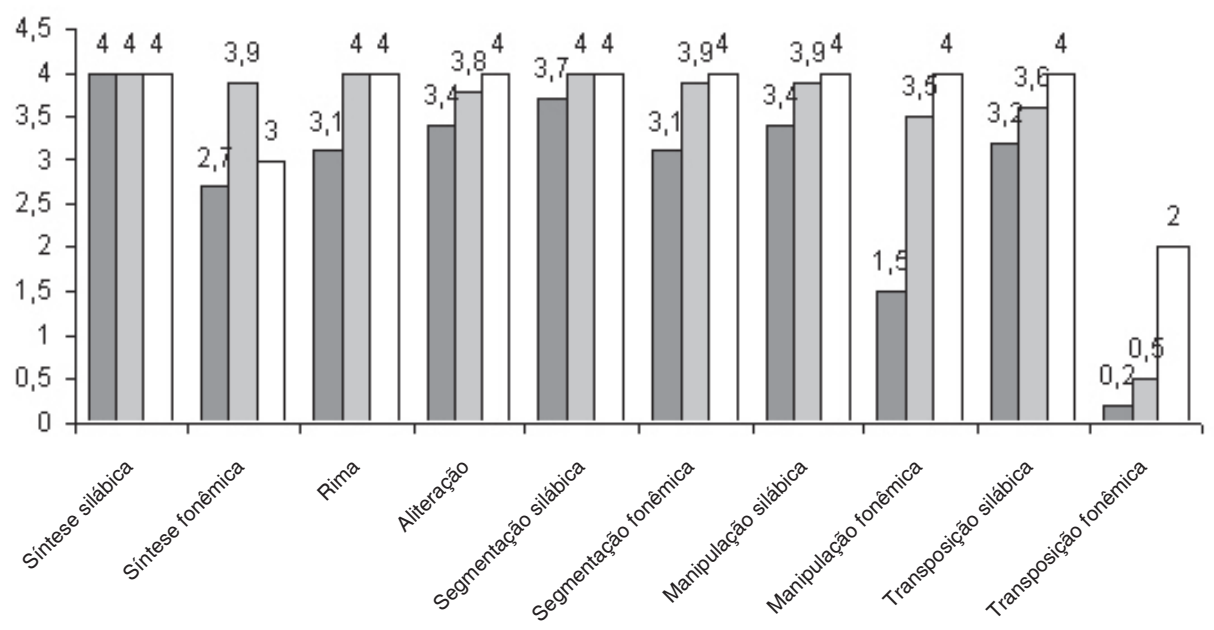

$$
\square \text { Inferior } \square \text { Médio } \square \text { Superior }
$$

\section{Figura 2 - Escores médios dos alunos em cada tarefa da PCFO por nível de desempenho escolar}


entanto, em apenas $20 \%$ das tarefas, o individuo com desempenho superior não atingiu a pontuação máxima.

Com o objetivo de testar se os escores obtidos pelos alunos com inferior desempenho são significativamente inferiores aos escores dos alunos com desempenho médio, aplicou-se o teste de MannWhitney (Wilcoxon), entre os escores obtidos em cada tarefa por cada um dos grupos.

A partir da Tabela 1, onde se encontra o valor da estatística teste (Z), assim como o valor-p, de cada teste realizado, conclui-se que nas tarefas síntese fonêmica, rima, segmentação fonêmica e manipu- lação fonêmica os escores dos alunos com nível de desempenho inferior são estatisticamente inferiores aos escores dos alunos com médio desempenho, pois o $p$-valor dos testes foi inferior a 0,05. Nas demais tarefas, os alunos de diferentes níveis possuem o mesmo desempenho.

Considerando o desempenho total dos alunos na prova de consciência fonológica, observou-se que a pontuação dos alunos com nível inferior é significativamente inferior a dos alunos com desempenho médio, ou seja, o desempenho final na consciência fonológica é diferente entre alunos com diferente desempenho acadêmico.

Tabela 1 - Valores obtidos nas tarefas da PCFO

\begin{tabular}{lcccc}
\hline $\begin{array}{l}\text { Tarefas de consciência } \\
\text { fonológica }\end{array}$ & $\begin{array}{c}\text { Médias do } \\
\text { grupo inferior }\end{array}$ & $\begin{array}{c}\text { Médias do } \\
\text { grupo médio }\end{array}$ & $\mathbf{Z}$ & p-valor \\
\hline Síntese silábica & 4,0 & 4,0 & $\mathrm{NA}$ & $\mathrm{NA}$ \\
Síntese fonêmica & 2,7 & 3,9 & 2,70 & 0,0070 \\
Rima & 3,1 & 4,0 & 3,03 & 0,0020 \\
Aliteração & 3,4 & 3,8 & 0,97 & 0,3300 \\
Segmentação silábica & 3,7 & 4,0 & 0,91 & 0,3600 \\
Segmentação fonêmica & 3,1 & 3,9 & 2,24 & 0,0250 \\
Manipulação silábica & 3,4 & 3,9 & 1,08 & 0,2800 \\
Manipulação fonêmica & 1,5 & 3,5 & 3,71 & 0,0002 \\
Transposição silábica & 3,2 & 3,6 & 0,58 & 0,5600 \\
Transposição fonêmica & 0,2 & 0,5 & 1,64 & 0,1000 \\
Total (soma das 10 tarefas) & 28,4 & 35,3 & 3,04 & 0,0020 \\
\hline
\end{tabular}

$Z$ = valor da estatística teste

Teste utilizado: Mann-Whitney (Wilcoxon)

\section{Desempenho escolar e consciência fonológica}

Através do teste de correlação de Pearson, calculou-se a correlação existente entre as variáveis: consciência fonológica (1), desempenho escolar (2), leitura (3), escrita (4) e aritmética (5). Os valores são demonstrados na Tabela 2.
Todas as correlações foram positivas e, a correlação mais forte encontrada neste estudo foi entre consciência fonológica e desempenho escolar $(0,88)$, seguida por consciência fonológica e leitura $(0,87)$, consciência fonológica e escrita $(0,76)$, leitura e escrita $(0,74)$, todas consideradas associações fortes. Consciência fonológica e aritmética,

Tabela 2 - Correlações entre as variáveis estudadas

\begin{tabular}{lccccc}
\hline VARIÁVEIS & $\mathbf{1}$ & $\mathbf{2}$ & $\mathbf{3}$ & $\mathbf{4}$ & $\mathbf{5}$ \\
\hline 1 - Consciência fonológica & 1 & 0,88 & 0,87 & 0,76 & 0,6 \\
2 - Desempenho escolar & & 1 & & & \\
3 - Leitura & & & 1 & 0,74 & 0,56 \\
4 - Escrita & & & 1 & 0,58 \\
5 - Aritmética & 40 & 143 & 70 & 35 & 38 \\
Pontuação máxima do teste & 32 & 86,3 & 58,7 & 17,3 & 10,4 \\
Média da pontuação obtida & 6 & 21,6 & 14,4 & 7,2 & 2 \\
Desvio padrão &
\end{tabular}

Teste utilizado: correlação de Pearson 
aritmética e escrita e, por último, aritmética e leitura, apesar de mais fracamente, também estão positivamente associadas com coeficiente de correlação iguais a 0,6, 0,58 e 0,56, respectivamente.

\section{DISCUSSÃO}

Na tarefa de rima da PCFO, que neste estudo houve diferença significativa entre os alunos de desempenho inferior e médio, de maneira geral, os resultados aqui encontrados discordam do posicionamento de alguns autores da literatura, que dizem que a habilidade de reconhecer rimas desenvolvese antes da aprendizagem da leitura e escrita ${ }^{3-9}$. Considerando esta questão, não deveria haver diferença significativa entre os alunos do grupo de desempenho inferior e médio, mas não foi o que ocorreu, os acadêmicos com desempenho médio foram superiores nesta tarefa. Mas este resultado concorda com outro estudo onde os autores perceberam que o seu grupo sem alfabetização, após intervenção, teve um desempenho superior na tarefa de rima comparado ao grupo com desempenho em leitura/escrita considerado baixo e sem intervenção ${ }^{10}$. Crianças com problemas de leitura e escrita cometem mais erros nas tarefas de rimas e que envolvem fonemas ${ }^{11}$.

Nas tarefas de aliteração, síntese silábica, segmentação silábica e manipulação silábica, os achados deste estudo concordam com a literatura, pois diversos autores dizem que estágios iniciais da consciência fonológica (consciência de aliteração e sílabas) contribuem para o desenvolvimento dos estágios iniciais do processo de leitura e que a síntese de sílabas é uma tarefa de fácil execução pela tendência natural das crianças em perceberem a fala segmentada ${ }^{3,8,9}$. Observou-se isso, pois não houve diferença entre os grupos no desempenho destas tarefas. Enquanto que na tarefa de aliteração, o achado deste trabalho é parecido com o encontrado em outro estudo, em que os autores observaram que o escore na tarefa de aliteração é significativamente maior que o escore na tarefa de rima ${ }^{12}$.

Já nas tarefas de síntese fonêmica, segmentação fonêmica e manipulação fonêmica, os achados concordam parcialmente com a literatura, pois autores afirmam que a consciência fonêmica (envolve tarefas de síntese, segmentação, manipulação e transposição fonêmica) resulta do contato com o código escrito, ou seja, esta habilidade se desenvolve no decorrer da aprendizagem da leitura/escrita e também auxilia na alfabetização, é um elo de reciprocidade ${ }^{3-9}$. Neste estudo, não houve diferença na transposição fonêmica, o que era esperado que existisse, mas não ocorreu. Diversos estudos mostram que as tarefas de consciência fonêmica estão mais relacionadas ao processo de alfabetização quando comparadas às tarefas envolvendo consciência silábica e intra-silábicas (rimas e onsets) logo, crianças alfabetizadas ou sem dificuldades na leitura/escrita realizam com maior êxito aquelas tarefas que envolvem consciência fonêmica 10,11,13,14.

Diversos estudos realizados prova a relação existente entre a leitura e a escrita com a consciência fonológica, seja estes estudos longitudinais, de correlação ou os que envolvem intervenção ${ }^{11-16}$, mas ignoram a aritmética, o que não houve nesta pesquisa.

Os resultados encontrados neste estudo demonstram que existe uma correlação positiva e forte entre desempenho acadêmico (leitura, escrita e aritmética) e consciência fonológica, como também foi fortemente a correlação entre consciência fonológica e leitura/escrita. Estes achados coincidem com o que foi encontrado em outros estudos, onde a leitura/escrita se correlacionava positivamente e de maneira significativa com a consciência fonológica ${ }^{12-15}$. Já outras pesquisas concluíram que enquanto a alfabetização se aprimora, ao mesmo tempo a consciência fonológica se lapida ${ }^{13}$, e crianças que antes da intervenção (terapia baseada em tarefas de consciência fonológica) tinham o desempenho em leitura-escrita inferior ao esperado e eram consideradas analfabetas, depois da intervenção foi significativa à melhora na alfabetização, igualando estas crianças a outras que eram alfabetizadas e que não sofreram intervenção ${ }^{10}$. Para a aprendizagem da leitura e escrita é necessário o principio alfabético e para alcançar este princípio, fatores como a consciência de que a fala pode ser segmentada, de que tais segmentos reaparecem em diversas palavras e que existem regras de correspondências grafo-fonêmicas, são necessários. Eles também afirmam que estes dois primeiros fatores essenciais para a formação do principio alfabético, constituem a consciência fonológica ${ }^{4}$.

Logo, tais resultados deste estudo e de outros citados acima permitem afirmar que a consciência fonológica desempenha um importante papel facilitador e indispensável no processo de aprendizagem, mas não se pode concluir qual é a direção do elo entre estas variáveis. A concepção mais aceita entre as pesquisas atuais é que existe uma reciprocidade entre ler/escrever e consciência fonológica, pois rimas, onsets e consciência de sílabas podem desenvolver-se sem o conhecimento da escrita, ao passo que a consciência fonêmica resulta, em parte, do contato com a escrita ${ }^{3}$.

Neste estudo percebeu-se que também há uma forte e positiva correlação entre leitura e consciência fonológica, demonstrando que quanto melhor o desempenho na leitura, melhor também é a habi- 
lidade metalingüística, a consciência fonológica. Certos autores verificaram a relação entre leitura e consciência fonológica, e encontraram que o grupo de bons leitores comparados ao de maus leitores tinha um desempenho superior e significativo em consciência fonológica o que concorda com o achado deste estudo ${ }^{16}$. O ser humano se utiliza de duas rotas para ler, uma é a rota fonológica e a outra é a lexical. A rota fonológica é a mais utilizada por crianças no inicio da alfabetização e compreende a habilidade de segmentar, de decodificar grafemas em fonemas e de sintetizar, habilidades estas que compõem a consciência fonológica, o que explica a relação entre estas variáveis ${ }^{4}$.

Também se calculou a correlação entre leitura e escrita, pois uma coisa é ler e outra é escrever, já que ler uma palavra corretamente não implica em grafá-la sem erros. O valor encontrado neste estudo coincide com os achados de alguns estudos que concluíram que bons leitores têm um desempenho melhor em escrita quando comparados aos maus leitores e que quanto pior é a escrita de um aluno, pior também é sua performance em leitura ${ }^{16,17}$. Isto ocorre, pois em determinado nível de aquisição da escrita, a criança percebe que existe uma relação entre a linguagem oral e a linguagem escrita. Essa ligação entre sons e letras é estabelecida através do princípio alfabético da escrita: palavras escritas contêm combinações de unidades visuais - letras ou combinações de letras - que são sistematicamente relacionadas às unidades sonoras das palavras - fonemas ${ }^{3}$.

Além de relacionar leitura e escrita, é importante também saber se estas tarefas "influenciam" a aritmética, pois são estas três tarefas que denominam qual o desempenho escolar de um aluno. Neste estudo, a correlação foi maior entre aritmética/escrita quando comparada à correlação aritmética/leitura. Apesar das correlações não serem tão fortes como na relação das outras variáveis, pode-se afirmar que alunos bons em tarefas de cálculos tendem a serem bons nas tarefas de leitura e escrita. Estudos compravam que a tarefa de aritmética está fortemente correlacionada com leitura/escrita e que bons leitores tendem a ter um desempenho em aritmética significativamente melhor que maus leitores ${ }^{14-16}$.

\section{CONCLUSÃO}

Neste estudo conclui-se que quanto mais desenvolvida é a consciência fonológica, melhor é a performance do aluno, que as tarefas que envolvem rima, síntese fonêmica, segmentação fonêmica e manipulação fonêmica, são realizadas com maior competência pelas crianças que possuem desempenho acadêmico médio, isto é, desempenho satisfatório para sua série escolar, estando mais relacionadas ao processo de alfabetização, que existe um elo entre as tarefas acadêmicas, isto é, o acadêmico que é melhor na tarefa de escrita, tende a ter bom desempenho em leitura e em aritmética e, quando um aluno diz que prefere ler, por exemplo, e não gosta de fazer contas, ele possui um desempenho em escrita melhor que em aritmética.

\section{AGRADECIMENTOS}

À mestre em estatística Daiane Aparecida Zuanetti por ter realizado os cálculos estatísticos deste estudo.

\section{ABSTRACT}

Purpose: to know the relationship between students' phonological awareness and their school performance, and to study if the students preference order or school subjects agree with their performance order obtained in the tests. Methods: 24 children in second degree of the public fundamental school was analyzed. They made a oral phonological awareness test and the school performance test. Every student with phonological disturbs was excluded from the study. Results: we observed that there is an association between preference and performance orders just in arithmetic and writing activities. In reading there is no association. Analyzing the results of the phonological awareness test, we observed that the group with medium school performance was more competent than students with lower school performance in activities such as: rhyme, phonemic synthesis, phonemic segmentation and phonemic manipulation. We also observed positive and strong correlation between the studied variables (arithmetic, reading, writing, phonological awareness and school performance). Conclusions: we concluded that children with more developed phonological awareness have better school performance than others students; activities of rhyme, synthesis, segmentation and manipulation phonemic are more related with literacy; there is association between preference order and performance in writing and arithmetic activities.

KEYWORDS: Underachievement; Child Language; Language Arts 


\section{REFERÊNCIAS}

1. Küster $A M B$, Húngaro RO, Casteleins VL. A fonoaudiologia educacional e a escola: muito a fazer, muito a pensar, muito a estudar. Rev Diálogo Educ. 2001; 2(4):129-38.

2. Marturano ED, Loureiro SR. O desenvolvimento socioemocional e as queixas escolares. In: Papalia DE, Olds SW. Desenvolvimento humano. Porto Alegre: Artes Médicas; 2000. p. 259-91.

3. Freitas GCM. Sobre a consciência fonológica. In: Lamprecht RR, organizador. Aquisição fonológica do português. Porto Alegre: Artmed; 2003. p. 179-92.

4. Capovilla AGS, Capovilla FC. Uma perspectiva geral sobre leitura, escrita e suas relações com consciência fonológica. In: Capovilla AGS, Capovilla FC. Problemas de leitura e escrita: como identificar, prevenir e remediar numa abordagem fônica. São Paulo: Memnon; 2000. p. 10-37.

5. Morais J, Kolinsky R, Alegria J, Scliar-Cabral L. Alphabetic literacy and psychological structure. Letras de Hoje. 1998; 33(4):61-79.

6. Wertzner HF. Fonologia. In: Andrade CRF, BefiLopes DM, Fernandes FD, Wertzner HF. ABFW: teste de linguagem infantil nas áreas de fonologia, vocabulário, fluência e pragmática. Barueri: PróFono; 2004. p. 5-30.

7. Stein LM. TDE: teste de desempenho escolar; manual para aplicação e interpretação. São Paulo: Casa do Psicólogo; 1994.

8. Capovilla AGS, Capovilla FC. Prova de consciência fonológica: desenvolvimento de dez habilidades da pré-escola a 2a série. Temas Desenvolv. 1998; 7(37):14-20.
9. Grégoire J, Piérart B. Avaliação dos problemas de leitura: os novos modelos teóricos e suas implicações diagnósticas. Porto Alegre: Artes Médicas; 1997.

10. Paula GR, Mota HB, Keske-Soares M. A terapia em consciência fonológica no processo de alfabetização. Pró-Fono. 2005; 17(2):174-84.

11. Salgado C, Capellini SA. Desempenho de leitura e escrita de escolares com transtorno fonológico. Psicol Esc Educ. 2004; 8(2):179-88.

12. Barrera S, Maluf MR. Consciência metalinguística e alfabetização: um estudo com crianças de primeira série do ensino fundamental. Psicol Reflex Crit. 2003; 16(3):491-502.

13. Santamaría VL, Leitão PB, Assencio-Ferreira VJ. A consciência fonológica no processo de alfabetização. Rev CEFAC. 2004; 6(3):237-41.

14. Capovilla AGS, Gütschow CRD, Capovilla FC. Habilidades cognitivas que predizem competência de leitura e escrita. Psicologia: Teoria e Prática. 2004; 6(2):13-26.

15. Valente F, Martins MA. Competências metalinguísticas e aprendizagem da leitura em duas turmas do $1 .^{\circ}$ ano de escolaridade com métodos de ensino diferentes. Análise Psicológica. 2004; 22(1):193-212.

16. Capovilla AGS, Capovilla FC, Suiter I. Processamento cognitivo em crianças com e sem dificuldades de leitura. Psicol Estud. 2004; 9(3):449-58.

17. Zucoloto KA, Sisto FF. Dificuldades de aprendizagem em escrita e compreensão de leitura. Inter Psicol. 2002; 2(6):157-66.

RECEBIDO EM: 15/08/2007

ACEITO EM: 14/02/2008

Endereço para correspondência:

Rua José João, 79

Porto Ferreira - SP

CEP: $13660-000$

Tel: (19) 3581-2855/ (19) 9275-8641/

(16) 3963-2572

E-mail: pati_zua@yahoo.com.br 